\title{
Anabolic androgenic steroid users: a tilt test study with young adult men
}

Carlos Gustavo Camara Puppin¹, Flávia de Souza Andrade Moraes ${ }^{1}$, Leonardo Raposo Rocha Gomes ${ }^{1}$, Andrews Marques do Nascimento ${ }^{1}$, Ewelyne Miranda de Lima ${ }^{1}$, Girlandia Alexandre Brasil ${ }^{1}$, Nazaré Souza Bissoli², Dominik Lenz ${ }^{1}$, Denise Coutinho Endringer ${ }^{1}$, Tadeu Uggere de Andrade ${ }^{1}$

${ }^{1}$ Department of Pharmacy, University Vila Velha, Vila Velha, Brazil

${ }^{2}$ Department of Physiological Sciences, Federal University of Espírito Santo, Vitória, Brazil

Submitted: 3 May 2019

Accepted: 4 July 2019

Arch Med Sci Civil Dis 2019; 4: e75-e83

DOI: https://doi.org/10.5114/amscd.2019.86992

Copyright $\odot 2019$ Termedia \& Banach

\section{Abstract}

Introduction: Anabolic androgenic steroids (AASs) can induce cardiac dysautonomia, which is related to arrhythmias, vasovagal syncope (VVS) and sudden death. The aim of this study was to determine whether the use of AASs increases the susceptibility for VVS or autonomic dysfunction in AAS users by the head-up tilt test (HUTT).

Material and methods: Cross-sectional observational study conducted with physically active young men, users (AAS group; $n=10$ ) and non-users (Control group, $n=13$ ) of AAS. The history of physical activity and age of each participant were recorded and the following examinations were performed: physical, biochemical, hormonal, electrocardiogram (ECG), 24-hour Holter recorder equipment. The 24-hour Holter and HUTT were conducted to detect the presence of arrhythmias/heart rate variability, and VVS/dysautonomia, respectively. Of the 28 participants recruited, 5 were excluded for not having completed the examinations.

Results: Compared with non-users, users of AAS showed an increase in aspartate aminotransferase (Control: $29.7 \pm 1.8$; AAS: $49.9 \pm 9.0 \mathrm{UI} / \mathrm{l} ; p<0.05$ ), in ventricular extrasystoles (Control: $2.5 \pm 2.3$; AAS: $14.9 \pm 11.2, p<0.05$ ), and reduction in the pNN50 index of Holter (Control: $24.3 \pm 4.0 \%$; AAS: 14.8 $\pm 4.0 \%, p<0.05)$. The HUTT showed that the maximum value of diastolic blood pressure was increased in the AAS user group (Control: $78.3 \pm 2.1$; AAS: $90.0 \pm 5.4 \mathrm{~mm} \mathrm{Hg}, p<0.05)$.

Conclusions: The study showed that the use of AAS is able to promote an autonomic dysfunction, with a ventricular arrhythmia. In addition it was found that among AAS users there was a positive result for the HUTT.

Key words: arrhythmias, head-up tilt test, Holter, sudden cardiac death, vasovagal syncope.

\section{Introduction}

Anabolic androgenic steroids (AASs) are synthetic derivatives of testosterone, with a chemical structure derived from cholesterol that is designed to maximize anabolic activity [1].

The abusive use of these drugs has gained popularity [2], and the abuse is widespread in gyms among athletes and non-athletes [3], particularly in young adults, to improve their performance, physical strength, exercise duration [1] and physical appearance [2] regardless of their adverse reactions.

\section{Corresponding author:}

Tadeu Uggere de Andrade Department of Pharmacy

University Vila Velha

Brazil

E-mail:

tadeu.andrade@uvv.br 
Carlos Gustavo Camara Puppin, Flávia de Souza Andrade Moraes, Leonardo Raposo Rocha Gomes, Andrews Marques do Nascimento, Ewelyne Miranda de Lima, Girlandia Alexandre Brasil, Nazaré Souza Bissoli, Dominik Lenz, Denise Coutinho Endringer,

Tadeu Uggere de Andrade

In relation to the cardiovascular system adverse effects, AASs are associated with infarction, resulting from electrical and structural remodeling [4], contractile dysfunction [5] and left ventricular hypertrophy associated with myocardial fibrosis [6], myocardial infarction, decreased left ventricular function and pulmonary embolisms [7, 8], and may also result in high blood pressure (BP) $[6,7,9]$.

Furthermore, AASs may increase the risk of cardiac arrhythmias and lead to sudden cardiac death [10, 11], especially in non-therapeutic abuse, although further pathophysiological mechanisms remain to be discovered [8].

The cardiovascular system is influenced by the sympathetic and parasympathetic nervous systems. The balance between these two systems determines the cardiovascular responses under various conditions, resulting in changes in $\mathrm{BP}$ and heart rate (HR). An increased parasympathetic nervous system response has antiarrhythmic and antifibrillatory effects, while the sympathetic nervous systems triggers arrhythmia and syncope [12, 13].

Syncope is defined as the sudden loss of consciousness with a loss of postural tone that passes rapidly and can spontaneously be recovered without sequelae [14]. Vasovagal syncope (VVS) is characterized by the abrupt onset of hypotension with or without bradycardia in a self-limited manner. These events are associated with dysautonomia in approximately $20-35 \%$ of syncope events, and it is a common cause of syncope in athletes $[10,14]$.

Considering that AASs can induce cardiac dysautonomia, which is related to arrhythmias, sudden death and VVS, and that the abuse of AAS is increasing in young adults, it was hypothesized that the abuse of AASs could facilitate the emergence of VVS. The aim of this study was therefore to evaluate the effect of AAS abuse on autonomic control of the heart and determine whether AASs cause an increased predisposition to VVS in young adult men.

\section{Material and methods}

\section{Subjects}

For the present study, 28 participants (physically active young men) with and without a history of abuse of AASs were recruited. After signing the consent form, participants were divided into two groups: the Control group comprising individuals who did not use AASs, and the AAS group. The following inclusion criteria were used: man, age between 18 and 30 years, regular physical exercise of a moderate intensity for 150 min per week for at least one year.

Inclusion criteria for the AAS group included a documented self-reported history of AAS use for at least 1 year and being in an "on-cycle" of AASs at the moment of the experimentation. Additionally, one of the AAS should be testosterone. Individuals from the Control group were included if they reported never having had used AAS. Individuals were excluded from the study if they reported to suffer from endocrine, metabolic, neurological, psychiatric, renal, hepatic or cardiovascular disorders history as well as any type of dysfunction/drug usage (including cocaine, amphetamines, and other cardiovascular stimulants). Another exclusion criterion was not attending the two sessions of the study.

\section{Design}

In this cross-sectional observational study, the participants were recruited by convenience. After recruitment, individuals were assessed in the facilities of the university (Laboratory of Cardiovascular Investigation and Head-up Tilt Test HUTT - Centre). Participants were assessed in two sessions: in the first, individuals of both groups self-reported their history of general health, AAS use and exercise training. Blood samples were collected, physical examination, ECG and Holter were performed. In the second session the individuals were submitted to the HUTT. Participants were requested to do $12 \mathrm{~h}$ of fasting (overnight) and not to do exercises for $24 \mathrm{~h}$ before the time of testing.

The study was approved by the Ethics Committee on Human Research of the University Vila Velha (CEP-UVV) under number 248509 of 04.17.2013. All participants provided written informed consent, and local ethics approval was obtained.

\section{Participants' history of exercise}

The participants answered a questionnaire about age, histories of previous diseases, family histories of sudden death, types of exercises performed, and the time spent on physical activity. The AAS users were asked about their history of use of AAS.

\section{Clinical assessment}

After answering the questionnaire, the subjects underwent a physical examination, which was performed by analyzing HR and BP with a digital device (Omron Health Care, Inc., Illinois, USA). Heart and lung auscultation and a measurement of body mass in kilograms and height in centimeters were used to calculate the body mass index (BMI) with a digital anthropometric balance (Welmy W300, São Paulo, SP, Brazil). The BP measurement was performed in accordance with the VII Brazilian Guideline of Arterial Hypertension [15].

\section{Laboratory examinations}

Blood samples were collected from the subjects to evaluate lipid and glycemic profiles and assess 
renal and liver function through an examination of biochemical parameters determined in accordance with the instructions of their respective commercial kits: triglycerides, total cholesterol, high-density lipoprotein (HDL cholesterol), low-density lipoprotein (LDL cholesterol) (LABTEST, Rio de Janeiro, RJ, Brazil); fasting glucose, urea, creatinine, aspartate aminotransferase (AST), and alanine aminotransferase (ALT) (Bioclin, Belo Horizonte, MG, Brazil). The LDL cholesterol was calculated using the Friedewald formula. As one of the inclusion criteria for the AAS group was the use of high doses of testosterone as at least one of the AASs used, the confirmation of AAS use was performed by evaluating the blood levels of testosterone via ELISA using a commercial kit (Coat-A-Count Total Testosterone, Diagnostic Products Corporation, Los Angeles, CA, USA). Laboratory tests were performed after fasting for $12 \mathrm{~h}$ and analyzed in the clinical laboratory of the university.

\section{Electrocardiogram (ECG)}

The electrocardiogram (ECG) of 12 derivations was conducted with an ECG AT1 (ECAFIX, São Paulo, SP, Brazil) while the participants were resting in the supine position. We evaluated $H R$, intra-atrial driving, atrioventricular and intraventricular conduction, ST segment analysis, and T and QT wave interval.

\section{4-hour Holter monitoring}

Excluding the presence of a cardiovascular disease in the participants was performed by ambulatory electrocardiography for $24 \mathrm{~h}$ (24-hour ECG/ Holter). In these tests, we analyzed the presence of cardiac arrhythmias and heart rate variability (HRV). The equipment used was the 24-hour ECG monitoring DMS 300 Holter recorder (DMS Inc., New York, NY, USA). The HRV analysis is performed using an index obtained by linear methods, time domain and frequency, and nonlinear methods [16]. This study used linear methods of analysis of the time domain expressed in milliseconds.

Parameters analyzed are as follows: the standard deviation of all normal-normal (NN) intervals (SDNN), the standard deviation of the averages of $\mathrm{NN}$ intervals in all 5-minute segments of the entire recording (SDANN); the mean of the standard deviations of all NN intervals for all 5-minute segments of the entire recording (SDNNi); the square root of the mean of the sum of the squares of differences between adjacent NN intervals (rMSSD), and the NN50 count divided by the total number of all NN intervals (pNN50). SDNN is the standard deviation of all normal RR intervals recorded over a time interval; SDANN represents the standard deviation of the normal RR intervals every $5 \mathrm{~min}$.
SDNNi is the standard deviation of the mean of the normal RR intervals every 5 min. The rMSSD refers to the square root of the mean of the squared differences between RR intervals over a time interval, and pNN50 is the percentage of the adjacent RR intervals longer than 50 ms [16].

The indexes SDNN, SDANN and SDNNi represent the sympathetic nervous systems and parasympathetic nervous system activities, but do not distinguish when the HRV is a result of increased sympathetic tone or decreased vagal activity [16, 17]. The rMSSD and pNN50 indexes are related to parasympathetic nervous system activity $[16,17]$.

\section{Head-up tilt test (HUTT)}

After analysis of the Holter recordings, participants underwent a HUTT, including BP measurements, $H R$, and an electrocardiographic recording for the diagnosis of VVS. The test confirmed the etiology of syncope [18] due to dysfunction of the ANS dysautonomia as well as susceptibility to VVS $[16,19,20]$.

In the supine position in a room with no noise, we verified the $B P$ and $H R$ and monitored and recorded the HR with the electrocardiograph leading in the D1, D2 and D3 positions. After resting for 20 min, the participant was held at a 70-degree tilt that was maintained for $40 \mathrm{~min}$ [20]. The individual participant was fixed with straps on the chest, hips and legs to prevent falls. Every $3 \mathrm{~min}$, the BP and HR were recorded. Individuals were observed throughout the rest period and tilt for any symptoms or signs, which were noted. For ethical reasons, the test was conducted without pharmacological sensitization with isoproterenol and nitrates [20].

The HUTT was considered positive by a decrease in BP with or without associated bradycardia [21]. The vasovagal responses were classified as mixed, cardioinhibitory or vasodepressive [14, 22]. In the mixed response, after the initial increase in $H R$ and $B P$, there was a decrease in $B P$ followed by a decrease in HR.

A cardioinhibitory response was characterized by a HR lower than $40 \mathrm{bpm}$ for a period longer than $10 \mathrm{~s}$ or an asystole greater than $3 \mathrm{~s}$ in duration with a fall of BP during or after the fall in HR. In the vasodepressor response, there occurs a progressive decrease in BP causes syncope and a smaller decrease than $10 \%$ of the maximum HR [14].

\section{Statistical analysis}

The quantitative data were expressed as mean \pm standard error of the mean (S.E.M.). To determine the difference between the means, Student's $t$ test was used with significance at $p<0.05$. We used the GraphPad Prism software (Version 5.0) for statistical analyses. The qualitative data were ex- 
Carlos Gustavo Camara Puppin, Flávia de Souza Andrade Moraes, Leonardo Raposo Rocha Gomes, Andrews Marques do Nascimento, Ewelyne Miranda de Lima, Girlandia Alexandre Brasil, Nazaré Souza Bissoli, Dominik Lenz, Denise Coutinho Endringer,

Tadeu Uggere de Andrade

pressed as percentages of frequencies, and analyses between the groups were performed using the $\chi^{2}$ test with significance accepted at $p<0.05$, using IBM SPSS Statistics software (Version 19.0.1).

\section{Results}

Twenty-eight participants were selected, who were divided into Control and AAS groups. However, 5 participants were excluded from the study because they did not attend their protocol sessions. Therefore, the groups were composed of 13 and 10 subjects in the Control and AAS groups, respectively (Figure 1 ).

The analysis of the demographic data did not reveal differences in terms of age and BMI of subjects from both study groups. In addition, there was no significant difference in the other biochemical parameters as depicted in Table I.

All participants performed some type of physical activity. The majority of participants performed bodybuilding (Control: 75\%; AAS: $80 \%$ ). In addition, $25 \%$ of the subjects in the Control group

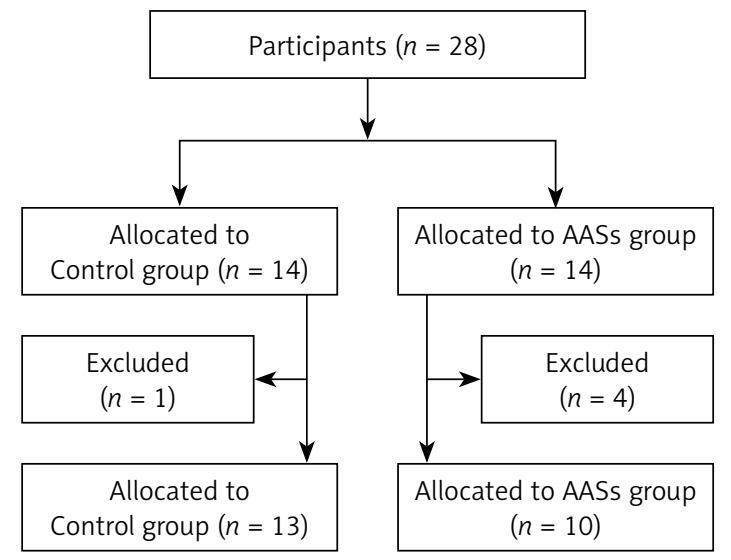

Figure 1. Flow chart of patients' recruitment and allocation

Table I. Results of the analysis of the demographic data and biochemical parameters of the subjects of the study from both groups

\begin{tabular}{|lcc|}
\hline Parameter & \multicolumn{2}{c|}{ Groups } \\
\cline { 2 - 3 } & Control & AAS \\
\hline Age $[$ years] & $25.8 \pm 3.6$ & $25.2 \pm 1.8$ \\
\hline BMI $\left[\mathrm{kg} / \mathrm{m}^{2}\right]$ & $25.5 \pm 0.6$ & $26.5 \pm 0.9$ \\
\hline Glucose $[\mathrm{mg} / \mathrm{dl}]$ & $89.9 \pm 1.6$ & $80.4 \pm 3.7$ \\
\hline Total cholesterol $[\mathrm{mg} / \mathrm{dl}]$ & $155.8 \pm 13.8$ & $139.7 \pm 13.5$ \\
\hline HDL cholesterol $[\mathrm{mg} / \mathrm{dl}]$ & $49.6 \pm 4.3$ & $35.2 \pm 3.9$ \\
\hline LDL cholesterol $[\mathrm{mg} / \mathrm{dl}]$ & $124.6 \pm 20.1$ & $125.5 \pm 17.0$ \\
\hline Triglycerides $[\mathrm{mg} / \mathrm{dl}]$ & $65.4 \pm 12$ & $69.5 \pm 8.9$ \\
\hline ALT $[$ Ul/l] & $38.4 \pm 7.4$ & $33.8 \pm 7.4$ \\
\hline
\end{tabular}

Control - non-users of anabolic androgenic steroids, AAS - users of anabolic androgenic steroids, BMI - body mass index, ALT - alanine aminotransferase; values are expressed as mean \pm S.E.M. and $20 \%$ of the subjects in the AAS group also practiced running. The majority of the subjects participated in physical activities 5 to 6 times per week (Control: 83.3\%; AAS: 62.5\%) and for 1 to $2 \mathrm{~h}$ per day. There was no significant difference in these parameters between the groups.

The results of the HUTT showed an increase in the maximum DBP parameter in AAS users compared to the Control group - (Table II). In addition, an individual of the anabolic group $(10 \% ; p<0.05)$ presented a positive test with a mixed response, while all subjects in the Control group were negative.

The AAS group presented changes in HRV and a significant increase in the density of ventricular arrhythmias (Table III). Differences in the 24-hour Holter were observed in the pNN50 parameter in the AAS group as well as the quantity of ventricular extrasystoles. There were no significant differences in the other parameters, as depicted in Table III.

The analysis of the hemodynamic data collected through clinical evaluation did not reveal differences in systolic blood pressure (SBP; Control: $121 \pm 5$; AAS: $128 \pm 2 \mathrm{~mm} \mathrm{Hg}$ ) and diastolic blood pressure (DBP; Control: $72 \pm 2$, AAS: $79 \pm 2 \mathrm{~mm} \mathrm{Hg}$ ) at rest between the control and the AAS group. However, AAS users presented a higher HR than the Control group (Control: $59.4 \pm 1.3$; AAS: $64 \pm 7$ bpm; $p<0.05$ compared with Control).

It was not possible to observe any changes in the ECG among study participants (Table IV). This study showed an increase in the hepatic enzyme AST in the AAS group (Control: $29.7 \pm 1.8$; AAS: $49.9 \pm 9.0 \mathrm{UI} / \mathrm{l} ; p<0.05$ ) (Figure 2).

It was observed that participants who reportedly used AASs had a higher plasma concentration of testosterone (Control: $757.9 \pm 60.1$; AAS: $1384.0 \pm 23 \mathrm{ng}$ / $\mathrm{ml} ; p<0.05$ compared with controls) (Figure 3 ). 
Table II. Results of the head-up tilt test of the subjects of the study from both groups

\begin{tabular}{|lcc|}
\hline Parameter & \multicolumn{2}{c|}{ Groups } \\
\cline { 2 - 3 } & Control & AAS \\
\hline Resting HR [bpm] & $65.0 \pm 2.7$ & $62.8 \pm 3.6$ \\
\hline Minimum HR [bpm] & $70.0 \pm 4.2$ & $67.3 \pm 2.0$ \\
\hline Maximum HR [bpm] & $91.3 \pm 3.8$ & $90.9 \pm 2.5$ \\
\hline Resting SBP [mm Hg] & $123.3 \pm 5.4$ & $128.8 \pm 0.8$ \\
\hline Minimum SBP [mm Hg] & $108.3 \pm 3.1$ & $111.9 \pm 4.6$ \\
\hline Maximum SBP [mm Hg] & $136.7 \pm 6.2$ & $131.3 \pm 5.7$ \\
\hline Resting DBP [mm Hg] & $72.8 \pm 1.6$ & $79.4 \pm 1.5$ \\
\hline Minimum DBP [mm Hg] & $70.0 \pm 2.2$ & $75.0 \pm 2.7$ \\
\hline Maximum DBP [mm Hg] & $78.3 \pm 2.1$ & $90.0 \pm 5.4^{*}$ \\
\hline
\end{tabular}

Control - non-users of anabolic androgenic steroids, AAS - users of anabolic androgenic steroids, SBP - systolic blood pressure, DBP diastolic blood pressure, $H R-$ heart rate; values are expressed as mean \pm S.E.M. ${ }^{*} p<0.05$.

Table III. Results of the 24-hour Holter of the subjects of the study from both groups

\begin{tabular}{|c|c|c|}
\hline \multirow[t]{2}{*}{ Parameter } & \multicolumn{2}{|c|}{ Groups } \\
\hline & Control & AAS \\
\hline SDNN - 24 h [ms] & $162.2 \pm 12.7$ & $157.6 \pm 11.4$ \\
\hline SDNN - index [ms] & $81.2 \pm 5.6$ & $77.5 \pm 6.3$ \\
\hline SDANN - index [ms] & $150.3 \pm 12.9$ & $136.3 \pm 10.7$ \\
\hline rMSSD [ms] & $47.2 \pm 3.9$ & $44.0 \pm 5.7$ \\
\hline pNN50 (\%) & $24.3 \pm 4.1$ & $14.8 \pm 4.1^{*}$ \\
\hline Mean HR [bpm] & $68.8 \pm 8.3$ & $72.6 \pm 2.4$ \\
\hline Minimum HR [bpm] & $41.8 \pm 3.9$ & $46.5 \pm 2.3$ \\
\hline Maximum HR [bpm] & $114.8 \pm 4.5$ & $123.6 \pm 2.5$ \\
\hline Quantity ventricular extrasystoles & $2.5 \pm 2.3$ & $14.9 \pm 11.2^{*}$ \\
\hline $\begin{array}{l}\text { Quantity supraventricular } \\
\text { extrasystoles }\end{array}$ & $2.2 \pm 1.2$ & $1.5 \pm 1.1$ \\
\hline ST segment & 0 & 0 \\
\hline QT interval & $455.0 \pm 8.2$ & $449.8 \pm 6.8$ \\
\hline
\end{tabular}

Control - non-users of anabolic androgenic steroids, AAS - users of anabolic androgenic steroids, SDNN-standard deviation of all normalnormal (NN) intervals, SDANN - standard deviation of the averages of NN intervals in all 5-minute segments of the entire recording, $r M S S D$ - square root of the mean of the sum of the squares of differences between adjacent NN intervals, pNN50-NN50 count divided by the total number of all NN intervals, HR - heart rate, values are expressed as mean \pm S.E.M. ${ }^{*} p<0.05$.

Table IV. Results of the electrocardiogram of the subjects of the study from both groups

\begin{tabular}{|lcccccc|}
\hline Groups & P $[\mathrm{ms}]$ & PR $[\mathrm{ms}]$ & QRS $[\mathrm{ms}]$ & ST & QT [ms] & Rhythm \\
\hline Control & $93.3 \pm 4.2$ & $183.3 \pm 8.0$ & $90.0 \pm 6.3$ & 0 & $371.7 \pm 12.8$ & Sinus rhythm \\
\hline AAS & $95.0 \pm 4.6$ & $168.8 \pm 6.4$ & $92.5 \pm 4.9$ & 0 & $383.8 \pm 12.8$ & Sinus rhythm \\
\hline
\end{tabular}

Control - non-users of anabolic androgenic steroids, AAS - users of anabolic androgenic steroids, values are expressed as mean \pm S.E.M.

All AAS users had significantly higher testosterone levels compared with the Control group, with values above the reference values and approximately 1.8 times higher than the Control group, confirming the use of AASs by individuals in this group and also the non-use of testosterone as an AAS by individuals in the Control group. 


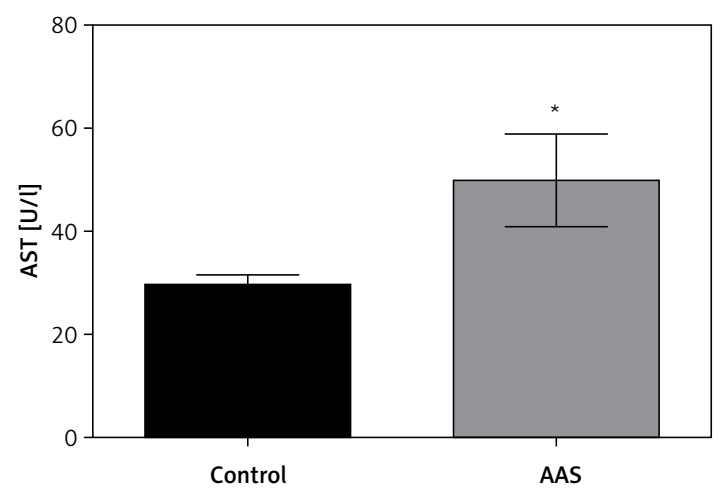

Figure 2. Evaluation of serum levels of the enzyme aspartate aminotransferase: (AST) aspartate aminotransferase; (Control) non-users of anabolic androgenic steroids; (AAS) users of anabolic androgenic steroids

Values are expressed as mean \pm S.E.M. ${ }^{*} p<0.05$

Of the subjects who used AASs, all used testosterone, $12 \%$ in an isolated manner and $88 \%$ in combination with other steroids. The most important AASs were used in combination, including nandrolone decanoate $(25 \%)$, aqueous testosterone/propionate (37.5\%), stanozolol (20\%), and others (5.5\%). The time of AAS use among the participants varied from 2 weeks (37.5\%) to 2 months (37.5\%). Regarding the previous use of AASs, $87.5 \%$ of participants reported that they had already used AASs on other occasions. When asked about the motive that caused them to discontinue use, $75 \%$ indicated having achieved their objectives, and $25 \%$ noted it was because of some side effect. The main reasons for use were: aes thetic purposes $(62.5 \%)$ or to enhance athletic performance $(25 \%)$. None of the participants had received medical supervision during their abuse of AASs. All the participants had information about the possible damaging effects of using these drugs; $87.5 \%$ had read the product label, but $25 \%$ did not understand the information. In relation to the undesirable effects presented after starting AASs, $87.5 \%$ of the participants reported having at least one symptom. The occurrence of increased aggression was reported in $35.3 \%$ of participants, followed by loss of sleep (29.4\%), headaches and migraines (11.8\%), the appearance of acne (5.9\%), sexual difficulty (5.9\%) and other symptoms (11.7\%).

\section{Discussion}

The main findings of this study were the increase in the maximum DBP parameter during the HUTT and the presence of cardiac arrhythmias, as well as heart rate variability in the AAS users, when compared to the Control group.

AASs promote a greater sensitivity to the effects of the sympathetic nervous systems. Also,

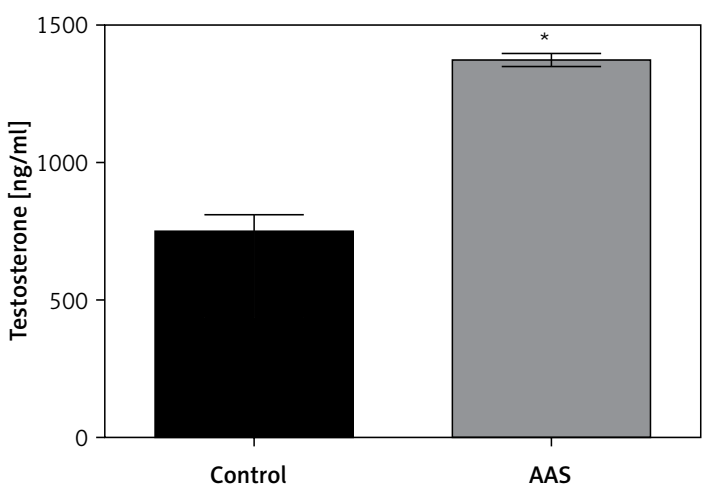

Figure 3. Evaluation of serum levels of testosterone: (Control) non-users of anabolic androgenic steroids; (AAS) users of anabolic androgenic steroids

Values are expressed as mean \pm S.E.M. ${ }^{*} p<0.05$

clinical and experimental data show that sympathetic activity is pro-arrhythmic [13]. Due to its high specificity, the HUTT is widely used to confirm the diagnosis of syncope, being able to identify the transient abstinence of the sympathetic activity and increase of vagal tone, occurring simultaneously after intense sympathetic activity, and, thus, characterize VVS [23-25].

The participants of the present study showed an increase in the maximum DBP for AAS users in the HUTT, which could indicate a higher probability of pre-syncope in these patients.

The data of the present study evidenced episodes of autonomic dysregulation commonly observed in patients with VVS $[23,24]$. Susceptibility to syncope could be explained by autonomic changes observed in the HRV of previous studies involving use of AASs. The HRV may reflect the changes found in the HR during the day, and the heart's ability to respond to various physiological and environmental stimuli, such as sleep and orthostatism, as a tool to assess the interaction between the sympathetic nervous system and parasympathetic nervous system [26].

HRV describes the oscillations of the intervals between consecutive heart beats (RR interval) that are related to actions of the autonomic nervous system (ANS) on the sinus node $[16,17]$. The control of the HR is influenced by the ANS, which relies on information from the baroreceptors, chemoreceptors, and atrial and ventricular receptors [16]. Abnormalities in HRV, measured during a 24hour period, are risk indicators related to sudden death in people with or without structural heart disease and in the general population $[27,28]$.

The AAS users presented a decrease in their parasympathetic activity, characterized by a decreased pNN50 index in the HRV analysis, which may be interpreted as dysautonomia. This result 
is in agreement with Maior et al. [4], who observed that recreational athletes using AASs had lower levels of pNN50 and rMSSD than the control group both at rest and after a submaximal exercise test; this suggests dysfunction in the ANS. Pereira-Junior et al. [7] obtained similar results evaluating Wistar rats using supraphysiological doses of nandrolone decanoate. The authors observed a significant reduction in the parasympathetic pNN50 index and concluded that impaired autonomic function could be the mechanism for cardiac arrhythmia and sudden death [7].

Marques Neto et al. [29] observed that sedentary and trained rats treated with nandrolone decanoate had a compromised parasympathetic index of HRV, which was reversed by the inhibition of the renin-angiotensin-aldosterone system using losartan and spironolactone. The imbalance in the ANS can alter the physiology of the circulatory system, increasing cardiovascular risk. The dysfunction of the ANS contributes to the reflex syncope [7], inducing arrhythmias and sudden cardiac death, which play a role in VVS [12].

Case reports have shown the relationship between VVS and severe arrhythmias leading to an increased risk of sudden cardiac death. Lepiece et al. [30] reported a case of VVS presenting ventricular fibrillation after prolonged asystole induced in the HUTT, requiring electric shock therapy to reverse, and that benefited from implantation of an automatic internal cardioverter defibrillator. Sucu and Davutoglu [31] induced VVS with prolonged asystole, requiring resuscitation procedures and subsequent implantation of permanent cardiac pacemakers, which successfully resolved the episodes.

The decreased pNN50 index of HRV may indicate parasympathetic dysfunction [32]. It may be assumed that the development of arrhythmias and sudden cardiac death is related with ANS dysfunction. Cardiac arrest is probably related to adrenergic stress, as evidenced in a pathological study [8].

In the AAS group, a significant increase in the quantity of ventricular extrasystoles was observed. Achar et al. [9] reported a higher incidence of ventricular arrhythmia in AAS users. In addition, electrical cardiac remodeling [33], signal-averaged ECG abnormalities [5] and dysautonomias evidenced by reduced parasympathetic nervous system activity in HRV have also been demonstrated.

The HUTT can be performed with pharmacological sensitization with the purpose of increasing the heart rate [34]. The authors did not address the pharmacological sensitization of HUTT, which may explain why the authors did not observe changes in $\mathrm{HR}$, as well as the sympathetic stimulation. In addition, the authors observed a decrease in parasympathetic activity and an increase in the quantity of ventricular extrasystoles in AAS users by Holter monitoring, which indicate changes in the autonomic nervous system of these patients. Probably, the age of the participants and the fact that they are all practitioners of physical activity contributed to the normal results found on the electrocardiogram [35].

The elevation of AST levels, a biochemical marker for changes in liver metabolism, indicates that the use of AASs may be inducing hepatotoxicity in the studied group, which is consistent with the current state of the scientific literature [3638]. AST usually increases in a standard dose-dependent manner, especially for those AASs which have a methyl group at the $\mathrm{C}-17$ position. This is proven for stanozolol [39], which was used by $20 \%$ of the AASs group in the present study.

The present study did not show substantial differences between the groups in terms of lipid profile, although HDL cholesterol was lower in the anabolic group. There are reports in the literature that androgens decrease HDL cholesterol concentrations and increase LDL cholesterol, favoring the development of coronary artery disease [40]. It must be taken into account that the effects of AAS abuse on LDL cholesterol can emerge late in the life time of the participants.

In this study, the use of testosterone (at anabolic concentration) as at least one of the AASs used by the AAS group, was used as an inclusion criterion with the aim of, by testosterone measurement in plasma, confirmation of AAS use.

The most important limitation was the size of the sample. A higher number of participants would enable better evaluation of the effect of AAS. Another limitation was the inability to follow the participants prospectively to assess the major adverse cardiovascular events. The population consisted exclusively of young men and therefore limited the understanding of the effects of AAS in women or older adults. Additionally, the authors were unable to perform the HUTT with pharmacological sensitization because of ethical concerns.

In conclusion, the results of this study demonstrated that the administration of AASs is able to promote autonomic dysfunction, with ventricular arrhythmia. Among AAS users, there was an increase in DBP during the HUTT and one positive result for the HUTT. In the control group, no changes in blood pressure were observed during the HUTT and none of the subjects were positive for VVS. Although, together with the dysautonomia observed, our results could indicate a predisposition to VVS, a conclusion that AAS use determines VVS cannot be made considering that only one subject was positive for VVS in the AAS group. However, the effects of AAS observed can lead to 
Carlos Gustavo Camara Puppin, Flávia de Souza Andrade Moraes, Leonardo Raposo Rocha Gomes, Andrews Marques do Nascimento, Ewelyne Miranda de Lima, Girlandia Alexandre Brasil, Nazaré Souza Bissoli, Dominik Lenz, Denise Coutinho Endringer,

Tadeu Uggere de Andrade

sudden cardiac death in AAS users, but further and larger studies are required to better correlate VVS with sudden cardiac death.

\section{Acknowledgments}

This work was financed in part by the Coordenação de Aperfeiçoamento de Pessoal de Nivel Superior - Brasil (CAPES; Finance Code 001), by the Fundação de Amparo a Pesquisa e Inovação do Espírito Santo (FAPES; grant number 0279/2016), and by Conselho Nacional de Desenvolvimento Científico e Tecnológico (CNPq: grant number 311925/2018-9).

\section{Conflict of interest}

The authors declare no conflict of interest.

\section{References}

1. Evans NA. Current concepts in anabolic-androgenic steroids. Am J Sports Med 2004; 32: 534-42.

2. Lawless CE, Olshansky B, Washington RL, et al. Sports and exercise cardiology in the United States: cardiovascular specialists as members of the athlete healthcare team. J Am Coll Cardiol 2014; 63: 1461-72.

3. Dunn M, White V. The epidemiology of anabolic-androgenic steroid use among Australian secondary school students. J Sci Med 2011; 14: 10-4.

4. Maior AS, Carvalho AR, Marques-Neto SR, Menezes $P$, Soares PP, Nascimento JH. Cardiac autonomic dysfunction in anabolic steroid users. Scand J Med Sci Sports 2013; 23: 548-55.

5. Sculthorpe N, Grace F, Jones P, Davies B. Evidence of altered cardiac electrophysiology following prolonged androgenic anabolic steroid use. Cardiovasc Toxicol 2010; 10: 239-43.

6. Maior AS, Menezes P, Pedrosa RC, Carvalho DP, Soares PP, Nascimento JH. Abnormal cardiac repolarization in anabolic androgenic steroid users carrying out submaximal exercise testing. Clin Exp Pharmacol Physiol 2010; 37: 1129-33.

7. Pereira-Junior PP, Chaves EA, Costa-E-Sousa RH, Masuda MO, de Carvalho AC, Nascimento JH. Cardiac autonomic dysfunction in rats chronically treated with anabolic steroid. Eur J Appl Physiol 2006; 96: 487-94.

8. Fineschi V, Baroldi G, Monciotti F, et al. Anabolic steroid abuse and cardiac sudden death: a pathologic study. Arch Pathol Lab Med 2001; 125: 253-5.

9. Achar S, Rostamian A, Narayan SM. Cardiac and metabolic effects of anabolic-androgenic steroid abuse on lipids, blood pressure, left ventricular dimensions, and rhythm. Am J Cardiol 2010; 106: 893-901.

10. Dickerman RD, Schaller F, Prather I, McConathy WJ. Sudden cardiac death in a 20-year-old bodybuilder using anabolic steroids. Cardiology 1995; 86: 172-3.

11. Kennedy MC, Laurence C. Anabolic steroid abuse and cardiac death. Med J Aust 1993; 158: 346-8.

12. Shen MJ, Zipes DP. Role of the autonomic nervous system in modulating cardiac arrhythmias. Circ Res 2014; 114: 1004-21.

13. Freitas J, Santos RM, Figueiredo V, Teixeira E, Carvalho M, de Freitas AF. Role of autonomic nervous system and hemodynamics in cardiovascular homeostasis after orthostatic stress. Rev Port Cardiol 2000; 19: 1241-74.
14. Brignole M, Menozzi C, Del Rosso A, et al. New classification of haemodynamics of vasovagal syncope: beyond the VASIS classification. Analysis of the pre-syncopal phase of the tilt test without and with nitroglycerin challenge. Vasovagal Syncope International Study. Europace 2000; 2 : 66-76.

15. Malachias MV, Souza WK, Plavnik FL, et al.; Sociedade Brasileira de Cardiologia; Sociedade Brasileira de Hipertensão; Sociedade Brasileira de Nefrologia. 7th Brazilian Guideline of Arterial Hypertension. Arq Bras Cardiol 2016; 107 (3 Suppl 3): 1-83.

16. Vanderlei LC, Pastre CM, Hoshi RA, Carvalho TD, Godoy MF. Basic notions of heart rate variability and its clinical applicability. Rev Bras Cir Cardiovasc 2009; 24: 205-17.

17. Ribeiro JP, Moraes Filho RS. Heart rate variability as an instrument for the investigation of the autonomic nervous system. Rev Bras Hipertens 2005; 12: 14-20.

18. Benditt DG, Ferguson DW, Grubb BP, et al. Tilt table testing for assessing syncope. American College of Cardiology. J Am Coll Cardiol 1996; 28: 263-75.

19. Balasubramaniyam N, Palaniswamy C, Aronow WS, et al. Association of corrected QT interval with long-term mortality in patients with syncope. Arch Med Sci 2013; 9: 1049-54.

20. Moya A, Sutton R, Ammirati F, et al. Guidelines for the diagnosis and management of syncope: the Task Force for the Diagnosis and Management of Syncope of the European Society of Cardiology (ESC). Eur Heart J 2009; 30: 2631-71.

21. Samoil D, Grubb BP. Vasovagal (neurally-mediated) syncope: pathophysiology, diagnosis and therapeutic approach. Eur J Cardiac Pacing and Electrophysiol 1992; 2: 234-41.

22. Sutton R, Peterson M, Brignole M, Ravielle A, Menozzi C, Giani P. Proposed classification for tilt induced vasovagal syncope. Eur J Cardiac Pacing Electrophysiol 1992; 2: $180-3$.

23. Owens AP, Low DA, Critchley HD, Mathias CJ. Emotional orienting during interoceptive threat in orthostatic intolerance: dysautonomic contributions to psychological symptomatology in the postural tachycardia syndrome and vasovagal syncope. Auton Neurosci 2018; 212: 42-7.

24. Gemein $C$, Roos $M$, Wolf $A$, et al. Tilt testing and what you should know about it - experience with 835 consecutive patients with syncope of unknown origin. Int J Cardiol 2018; 258: 90-6.

25. Kochiadakis GE, Papadimitriou EA, Marketou ME, Chrysostomakis SI, Simantirakis EN, Vardas PE. Autonomic nervous system changes in vasovagal syncope: is there any difference between young and older patients? Pacing Clin Electrophysiol 2004; 27: 1371-7.

26. Rajendra AU, Paul Joseph K, Kannathal N, Lim CM, Suri JS. Heart rate variability: a review. Med Biol Eng Comput 2006; 44: 1031-51.

27. Routledge HC, Chowdhary S, Townend JN. Heart rate variability - a therapeutic target? J Clin Pharm Ther 2002; 27: 85-92.

28. Tsuji H, Larson MG, Venditti FJ Jr, et al. Impact of reduced heart rate variability on risk for cardiac events. The Framingham Heart Study. Circulation 1996; 94: 2850-5.

29. Marques Neto SR, da H Silva A, dos Santos MC, Ferraz EF, Nascimento JH. The blockade of angiotensin AT1 and aldosterone receptors protects rats from synthetic androgen-induced cardiac autonomic dysfunction. Acta Physiol (Oxf) 2013; 208: 166-71.

30. Lepiece C, Dormal F, Blommaert D. Vasovagal syncope initiating ventricular fibrillation in a healthy subject. Acta Cardiol 2013; 68: 635-8. 
31. Sucu M, Sari I, Davutoğlu V. A case of prolonged asystole during head-up tilt testing. Turk Kardiyol Dern Ars 2009; 37: 345-7.

32. Freeman R, Chapleau MW. Testing the autonomic nervous system. Handb Clin Neurol 2013; 115: 115-36.

33. Nascimento JH, Medei E. Cardiac effects of anabolic steroids: hypertrophy, ischemia and electrical remodelling as potential triggers of sudden death. Mini Rev Med Chem 2011; 11: 425-9.

34. Brignole M, Alboni P, Benditt DG, et al. Guidelines on management (diagnosis and treatment) of syncope-update 2004. Executive Summary. Eur Heart J 2004; 25: 2054-72.

35. Gagliano-Jucá T, Içli TB, Pencina KM, et al. Effects of testosterone replacement on electrocardiographic parameters in men: findings from two randomized trials. J Clin Endocrinol Metab 2017; 102: 1478-85.

36. Schwingel PA, Cotrim HP, Salles BR, et al. Anabolic-androgenic steroids: a possible new risk factor of toxicant-associated fatty liver disease. Liver Int 2011; 31: 348-53.

37. Modlinski R, Fields KB. The effect of anabolic steroids on the gastrointestinal system, kidneys, and adrenal glands. Curr Sports Med Rep 2006; 5: 104-9.

38. Conway AJ, Handelsman DJ, Lording DW, Stuckey B, Zajac JD. Use, misuse and abuse of androgens. The Endocrine Society of Australia consensus guidelines for androgen prescribing. Med J Aust 2000; 172: 220-4.

39. Stimac D, Milić S, Dintinjana RD, Kovac D, Ristić S. Androgenic/anabolic steroid-induced toxic hepatitis. J Clin Gastroenterol 2002; 35: 350-2.

40. Rosano GM, Cornoldi A, Fini M. Effects of androgens on the cardiovascular system. J Endocrinol Invest 2005; 28 (3 Suppl): 32-8. 